\title{
An Elderly Woman with Anti-neutrophil Antibody-positive Agranulocytosis Who Responded to High-dose Intravenous Methylprednisolone
}

\author{
Shiro Koh ${ }^{1}$, Hideo Koh ${ }^{1}$, Yuki Kubo ${ }^{2}$, Maiko Kuroda ${ }^{1}$, Mitsutaka Nishimoto ${ }^{1}$, \\ Takuro Yoshimura ${ }^{1}$, Yasuhiro Nakashima ${ }^{1}$, Takahiko Nakane ${ }^{1}$, Hirohisa Nakamae ${ }^{1}$, \\ Masahiko Ohsawa $^{2}$ and Masayuki Hino ${ }^{1}$
}

\begin{abstract}
:
Although anti-neutrophil antibodies (ANAs) often exist and immunoreaction may be involved in agranulocytosis, few reports have so far described ANA-positive cases of agranulocytosis with an unknown etiology. We herein describe the case of a 69-year-old woman who presented with ANA-positive agranulocytosis. In this case, both the withdrawal of the drugs that had possibly caused neutropenia and the use of granulocytecolony stimulating factor (G-CSF) were ineffective treatment measures. Approximately 2 weeks after the discontinuation of the suspected drugs, we initiated corticosteroid pulse therapy; the neutrophil count recovered by day 19 of steroid therapy. High-dose methylprednisolone therapy should thus be considered for patients demonstrating ANA-positive agranulocytosis with an unknown etiology that is refractory to G-CSF treatment.
\end{abstract}

Key words: agranulocytosis, anti-neutrophil antibody, high-dose methylprednisolone

(Intern Med 56: 2199-2203, 2017)

(DOI: 10.2169/internalmedicine.8268-16)

\section{Introduction}

Agranulocytosis is a well-known but rare disease that presents with severe neutropenia mainly due to drug side effects. Two major mechanisms of agranulocytosis are reported: "direct" drug toxicity to myeloid precursors and "indirect" immune- or antibody-mediated responses (1-3). In cases of drug-induced agranulocytosis, the immediate discontinuation of the causative drugs is vital and the use of granulocyte colony stimulating factor (G-CSF) may be effective (4). Several case reports have shown the effectiveness of corticosteroids for drug-induced agranulocytosis (5-7). However, there is a paucity of information focusing on nondrug-induced agranulocytosis cases related to anti-neutrophil antibody. To our knowledge, only one case report of severe antibody-mediated non-drug-induced agranulocytosis that was treated with high-dose steroid treatment has been pub- lished to date (8).

We herein describe the case of an elderly patient with anti-neutrophil antibody-positive agranulocytosis with no obvious agranulocytosis etiology that did not respond to GCSF administration, but ultimately responded to corticosteroid therapy.

\section{Case Report}

A 69-year-old woman with progressive leucopenia and persistent fever was admitted to our hospital. Two months prior to the admission, she presented with a skin rash of unknown etiology that was ultimately managed by the intermittent use of bepotastine besilate and very low dose prednisolone (PSL) at a dose of $1 \mathrm{mg} /$ day. She thereafter developed a high fever, sore throat, and general fatigue for 9 days despite antibiotic treatment, and blood tests revealed a remarkably decreased leucocyte count. At admission (Day 1),

${ }^{1}$ Hematology, Graduate School of Medicine, Osaka City University, Japan and ${ }^{2}$ Department of Diagnostic Pathology, Graduate School of Medicine, Osaka City University, Japan

Received: September 26, 2016; Accepted: December 19, 2016; Advance Publication by J-STAGE: August 1, 2017

Correspondence to Dr. Hideo Koh, hide_koh@ med.osaka-cu.ac.jp 
Table. Blood Examination Findings of the Patient on Admission.

\begin{tabular}{|c|c|c|c|c|c|c|c|c|}
\hline & & Normal range & & & Normal range & & & ormal range \\
\hline WBC $\left(\times 10^{9} / \mathrm{L}\right)$ & 1.4 & $43-80$ & $\mathrm{UN}(\mathrm{mg} / \mathrm{dL})$ & 15 & $7-18$ & ANA & $\begin{array}{l}\times 640 \\
\text { Speckled pattern }\end{array}$ & Negative \\
\hline Stabs, segs (\%) & 0 & $49.5-71$ & Cre $(\mathrm{mg} / \mathrm{dL})$ & 0.88 & $0.40-0.90$ & $\mathrm{RF}$ & Negative & Negative \\
\hline Lymphocytes (\%) & 99 & $26.6-46.6$ & $\mathrm{CRP}(\mathrm{mg} / \mathrm{dL})$ & 7.57 & $0-0.4$ & $\begin{array}{l}\text { Anticentromere } \mathrm{Ab} \\
\text { (index) }\end{array}$ & 175 & $<10.0$ \\
\hline Monocytes (\%) & 1 & $2.3-7.7$ & Ferritin (ng/mL) & 329.2 & $4.6-204.0$ & $\begin{array}{l}\text { Anti-dsDNA Ab } \\
\text { (IU/mL) }\end{array}$ & $<5.0$ & $<5.0$ \\
\hline Eosinophils (\%) & 0 & $0.2-6.8$ & Vit $B_{12}(p g / m L)$ & 838 & $233-914$ & Anti-Sm Ab & Negative & Negative \\
\hline Basophils (\%) & 0 & $0.0-1.8$ & Folate (ng/mL) & 8.3 & $3.6-12.9$ & LA (RATIO) & 1.2 & $<1.2$ \\
\hline $\mathrm{RBC}\left(\times 10^{12} / \mathrm{L}\right)$ & 3.43 & $3.95-4.65$ & sIL-2 R (U/mL) & 1,180 & $124-466$ & $\begin{array}{l}\text { Cardiolipin } \mathrm{Ab} \\
(\mathrm{U} / \mathrm{mL})\end{array}$ & $<8.0$ & $<8.0$ \\
\hline $\mathrm{Hb}(\mathrm{g} / \mathrm{dL})$ & 9.5 & $11.3-47.0$ & Free T3 $(\mathrm{pg} / \mathrm{mL})$ & 2.1 & $2.30-4.00$ & HBsAg & negative & Negative \\
\hline $\operatorname{HCT}(\%)$ & 29.5 & $36.0-47.0$ & Free T4 $(\mathrm{pg} / \mathrm{mL})$ & 1.16 & $0.90-1.70$ & $\mathrm{HBs} A b(\mathrm{mIU} / \mathrm{mL})$ & 13.2 & Negative \\
\hline RETIC (\%) & 6.1 & $0.5-2$ & TSH (IU/mL) & 1.020 & $0.500-5.000$ & $\mathrm{HBcAb}$ & Negative & Negative \\
\hline $\operatorname{PLT}\left(\times 10^{9} / \mathrm{L}\right)$ & 263 & $180-340$ & $\operatorname{IgG}(\mathrm{mg} / \mathrm{dL})$ & 1,829 & $870-1,700$ & HB virus-DNA & Negative & Negative \\
\hline $\mathrm{TP}(\mathrm{g} / \mathrm{dL})$ & 7.1 & $6.5-8.5$ & $\operatorname{IgA}(\mathrm{mg} / \mathrm{dL})$ & 240 & $110-410$ & $\mathrm{HCV} \mathrm{Ab}$ & Negative & Negative \\
\hline $\mathrm{Alb}(\mathrm{g} / \mathrm{dL})$ & 3.3 & $3.5-5.0$ & $\operatorname{IgM}(\mathrm{mg} / \mathrm{dL})$ & 103 & $46-240$ & EBV VCA IgG & $\times 10$ & $<\times 10$ \\
\hline T-Bil (g/dL) & 0.4 & $0.2-1.0$ & PT-INR & 1.00 & $0.9-1.1$ & EBV VCA IgM & $<\times 10$ & $<\times 10$ \\
\hline AST (IU/L) & 16 & $13-33$ & APTT (s) & 45.2 & $25.0-40.0$ & EBNA & Indeterminable & $<\times 10$ \\
\hline ALT (IU/L) & 16 & $6-27$ & $\begin{array}{l}\text { Fibrinogen } \\
(\mathrm{mg} / \mathrm{dL})\end{array}$ & 534 & $200-400$ & CMV antigenemia & Negative & Negative \\
\hline$\gamma$-GTP (IU/L) & 87 & $5-60$ & $\mathrm{FDP}(\mu \mathrm{g} / \mathrm{mL})$ & 5.7 & $0-10.0$ & HPV B19-IgM & Negative & Negative \\
\hline $\operatorname{ALP}(\mathrm{IU} / \mathrm{L})$ & 421 & $115-359$ & \multirow{2}{*}{\multicolumn{3}{|c|}{ Cross mixing test Inhibitory pattern }} & HIV & Negative & Negative \\
\hline LDH (IU/L) & 125 & $119-229$ & & & & TB-INF- $\gamma$ & Negative & Negative \\
\hline
\end{tabular}

TP: total protein, Alb: albumin, T-Bil: total bilirubin, AST: aspartate transaminase, ALT: alanine transaminase, $\gamma$-GTP: gamma-glutamyl transpeptidase, ALP: alkaline phosphatase, LDH: lactate dehydrogenase, UN: urea nitrogen, Cre: creatinine, CRP: C-reactive protein, Vit $\mathrm{B}_{12}$ : vitamin $\mathrm{B}_{12}$, sIL2-R: soluble interleukin-2 receptor, TSH: thyroid-stimulating hormone, PT-INR: international normalized ratio of prothrombin time, APTT: activated partial thromboplastin time, FDP: fibrin/fibrinogen degradation products, ANA: antinuclear antibody, RF: rheumatoid factor, Ab: antibody, LA: lupus anticoagulant, HB: hepatitis B, HBsAg: hepatitis B surface antigen, HBsAb: hepatitis B surface antibody, HBcAb: hepatitis B core antibody, HCV: hepatitis C virus, EBV: Epstein-Barr virus, VCA: virus capsid antigen, EBNA: antibody responses to EBV-determined nuclear antigen, CMV: cytomegalovirus, HPV: human parvovirus, HIV: human immunodeficiency virus, TB-INF- $\gamma$ : tuberculosis interferon-gamma

she had a fever $\left(\geq 38^{\circ} \mathrm{C}\right)$ and pharyngeal erythema, but no other signs or symptoms of hematological malignancies or autoimmune disease, such as splenomegaly, skin rash, or joint pain. She had been administered anti-hypertensive drugs (amlodipine besilate), anti-dyslipidemia drugs (fenofibrate), and thrombosis prophylactic aspirin for several years as well as ursodeoxycholic acid for non-viral hepatitis for the previous year.

The laboratory findings are shown in Table. The patient showed a decreased absolute neutrophil count, below the limit of detection, and mild anemia with an increased reticulocyte count. Serology testing revealed the presence of antinuclear and anticentromere antibodies. A bone marrow biopsy revealed severe hypoplasia without any significant dysplasia (Fig. 1). The number of myeloid cells were markedly decreased, and also the number of megakaryocytes was decreased in the nucleated cells, while lymphocytes were predominant. A chromosomal analysis showed a normal karyotype. Abdominal ultrasonography revealed moderate splenomegaly and hepatic steatosis.

Although these findings suggested a diagnosis of aplastic anemia, it was ruled out for the following reasons: the degree of the red blood cell count reduction was relatively mild compared to that of neutrophils, and the platelet count was in the normal range. Thus, we made a provisional diagnosis of drug-induced agranulocytosis and discontinued all drugs (aspirin at Day 7 and the other drugs at Day 1) suspected of causing the agranulocytosis. On Day 4, we initiated G-CSF treatment and conducted laminar air flow isolation. Although the use of broad-spectrum antibiotics resolved the high fever and pharyngalgia, the neutrophil count did not return to normal. She then developed severe pneumonia. Computed tomography (CT) performed on Day 11 revealed an anterior mediastinal tumor (Fig. 2a). A fluorodeoxyglucose positron emission tomography (FDG-PET) examination performed on Day 23 showed an abnormal uptake [maximum standardized uptake value (max SUV), 7.1] in the lymph nodes and the lesion (Fig. 2b), which was suspected to be malignant. Since these observations suggested that the severe, persistent leukopenia could have been caused by immune-mediated or paraneoplastic syndrome, we decided to try immunosuppressive therapy. Further, we considered performing thymectomy because of the possible association between pure white cell aplasia and the presence of thymoma (9). However, we later rejected that approach because the FDG uptake in the lymph nodes was higher than that in the anterior mediastinal tumor, which suggested the absence of a thymoma. Thus, we initiated high-dose in- 

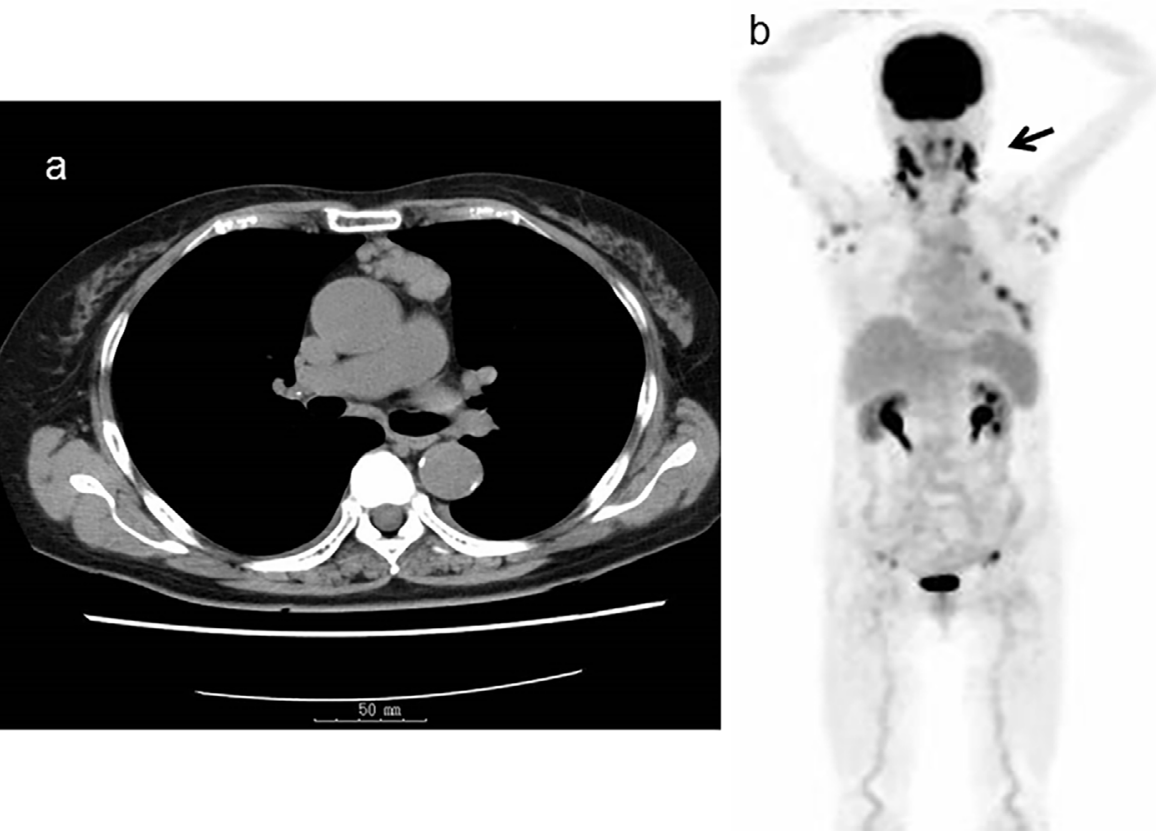

Figure 1. a: A computed tomography scan showing an anterior mediastinal tumor. b: A positron emission tomography scan revealing an abnormal fluorodeoxyglucose uptake in the lymph nodes of the neck, supraclavicular region, pulmonary hilum, and inguinal region [maximum standardized uptake value (SUV), 7.1], spleen (SUV, 3.4), left lung (SUV, 5.6), and mediastinal tumor (SUV, 3.0).
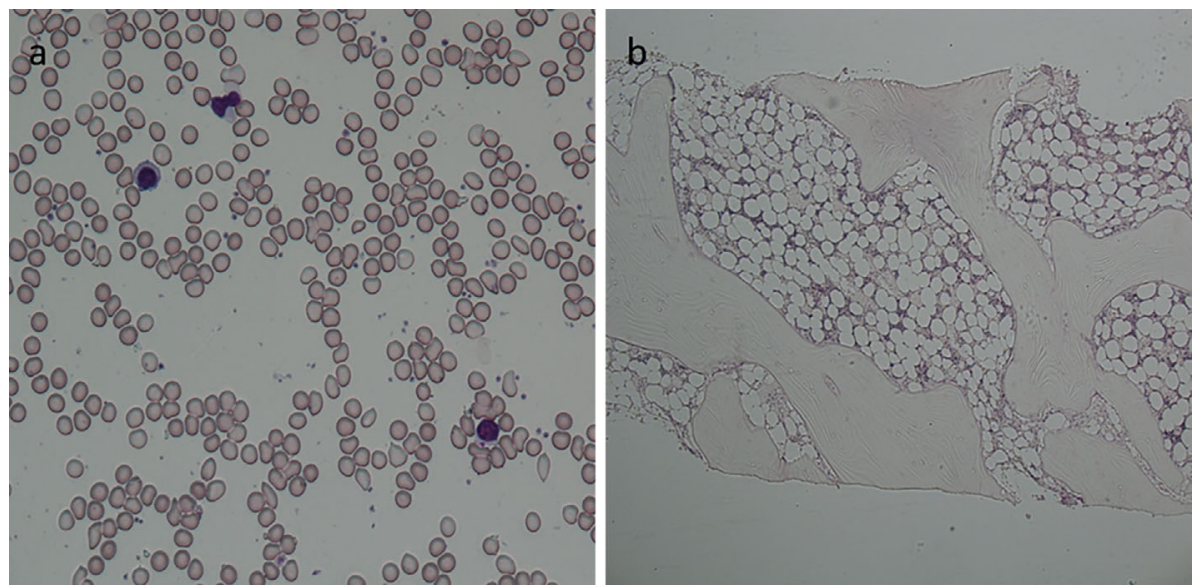

Figure 2. a: A bone marrow smear showing severe hypoplasia. In addition, the number of granulocyte progenitors and erythroblasts markedly decreased. b: A bone marrow biopsy smear showing severe hypoplasia without any infiltration of malignant cells.

travenous methylprednisolone (mPSL) therapy $(1 \mathrm{~g} /$ day for 3 days) from Day 20 and then administered PSL (1 mg/kg), while also continuing the G-CSF therapy. During the treatment, she tested positive for anti-neutrophil antibodies by the granulocyte immunofluorescence test (GIFT) (10). However, we did not detect the anti-neutrophil antibody in other techniques, and the correspondent antigen was not identified (11-14). At Day 40 (19 days after corticosteroid initiation), the neutrophil count increased to $312 / \mu \mathrm{L}$ and then gradually returned to the normal range. However, despite the administration of broad-spectrum antibiotics and anti-mold drugs, the patient died of Aspergillus pneumonia and cerebral hemorrhage, possibly due to disseminated intravascular coagulation (DIC) on Day 46. An autopsy revealed the thymic tumor to be a cyst, and no findings of malignancy were observed in the lymph nodes, spleen, or other tissues.

\section{Discussion}

We herein describe a case of anti-neutrophil antibodypositive severe agranulocytosis that did not seem to be druginduced. The administration of G-CSF alone for 16 days was ineffective. The neutrophil counts recovered by Day 40 (19 days after corticosteroid administration); however, the patient died of a mold infection and cerebral hemorrhage, possibly due to DIC prior to granulocyte recovery. The ear- 
lier administration of mPSL may have be able to successfully treat the patient, although the ideal management of immune-mediated neutropenia remains controversial (1).

We were unable to identify the cause of the neutropenia in this patient except for a positive anti-neutrophil antibody result. According to the differential diagnosis for this case, we ruled out aplastic anemia because the platelet count on admission remained within the normal range and corticosteroids were effective, although the absence of neutrophils in the peripheral blood and myeloid precursors in the bone marrow suggested fulminant aplastic anemia (15). The duration from the termination of oral medicine until the neutrophil recovery was 33-40 days, which is much longer than that (4-24 days) reported in previous studies on druginduced agranulocytosis $(16,17)$. The major cause of agranulocytosis is reportedly drug-induced (3); other causes, although less frequent, include infection, autoimmunemediated [autoimmune neutropenia (AIN)] (18-20), or with an unknown etiology. In adult patients, primary AIN is rare, but it has a benign clinical course. Accordingly, this cause was unlikely in our case. In contrast, secondary AIN is more frequent in adults, and its prognosis depends on the underlying diseases (18-20). Johnsen et al. reported a case of a patient with secondary AIN, and the case showed agranulocytosis with anti-neutrophil antibody and a past history of Crohn's disease that responded to G-CSF and corticosteroid treatment (8). They described that some immune-mediated reactions through autoantibodies directed towards the early myeloid cells may be associated with the development of agranulocytosis. Our patient presented with similar manifestations, including anti-neutrophil antibody positivity; however, no primary disease could be clearly identified. In both their and our cases, the responses to steroids seem to support an immune-mediated cause of the agranulocytosis. However, the exact contributions of anti-neutrophil antibodies to the development of agranulocytosis remain unclear, and further investigation is needed to elucidate the mechanism.

The gold standard method for measuring anti-neutrophil antibody has yet to be sufficiently established (21). Although the GIFT, granulocyte agglutination test, and monoclonal antibody immobilization of granulocyte antigens tests are commonly used, these methods may not be sufficient when performed alone (21). The International Granulocyte Serology Workshop recommends using at least two methods (22). In this case, only one of several methods yielded positive results. However, considering the possibility of a false negative result due to insufficient sensitivity and the possibility of the existence of antibodies which respond to the unknown antigens on myeloid cells other than human neutrophil antigen (HNA)-1a, 1b, 2a, Siglec-14 and CD36 antigens (11-14), one may consider starting immunosuppressive treatment even though only one test shows a positive result, or regardless.

In drug-induced agranulocytosis, no treatment options other than causative drug termination have so far been estab- lished. The administration of G-CSF for agranulocytosis is controversial (4). On the other hand, its use for treating primary AIN in pediatric patients is recommended. In adult patients, its effectiveness depends on the underlying diseases (23). The optimal treatment for AIN in cases that are refractory to G-CSF has not yet been established, but the use of corticosteroids, immunosuppressants, and intravenous gamma-globulin has been reported (20). In patients with etiology-unknown agranulocytosis, who tested positive for anti-neutrophil antibody as was seen in this case, immunosuppressive therapy including high-dose corticosteroids should be attempted while carefully managing fungal infections, because not only profound prolonged neutropenia, but also the administration of corticosteroids are well-known risk factors for fungal infections (24).

Some limitations associated with this case report include the fact that we did not perform biopsies of the skin, liver, and thymic gland when the patient was alive and we used high-dose mPSL with the understanding that steroids may mask the manifestations of underlying autoimmune disease. However, the masking of manifestations, which indicates a very high efficacy of immunosuppressive therapy, may suggest the presence of immune-mediated neutropenia.

In conclusion, we herein described an adult case of steroid-responsive agranulocytosis with anti-neutrophil autoantibody suspected of having an immune-related pathophysiology. Our findings suggest that the empiric administration of high-dose mPSL might be useful for such cases with severe agranulocytosis that fail to respond to G-CSF administration.

\section{The authors state that they have no Conflict of Interest (COI).}

\section{Acknowledgement}

The authors thank the laboratory of the Japanese Red Cross Society for examining our patient's samples using several assay methods (11-14).

\section{References}

1. Palmblad J, Dufour C, Papadaki HA. How we diagnose neutropenia in the adult and elderly patient. Haematologica 99: 11301133, 2014.

2. Tesfa D, Keisu M, Palmblad J. Idiosyncratic drug-induced agranulocytosis: possible mechanisms and management. Am J Hematol 84: 428-434, 2009.

3. Johnston A, Uetrecht J. Current understanding of the mechanisms of idiosyncratic drug-induced agranulocytosis. Expert Opin Drug Metab Toxicol 11: 243-257, 2015.

4. Pick AM, Nystrom KK. Nonchemotherapy drug-induced neutropenia and agranulocytosis: could medications be the culprit? J Pharm Pract 27: 447-452, 2014.

5. Caldwell AL, Adams JW, Anderson JF, Dick AA. Agranulocytosis treated with cortisone. Can Med Assoc J 62: 506-507, 1950.

6. Virkkunen M. Corticotropin and cortisone in the treatment of agranulocytosis and thrombocytopenic purpura; report of four cases. AMA Arch Intern Med 90: 580-586, 1952.

7. Hamada N, Itoh K, Mototani N, Nishikawa Y, Mimura T, Morii H. Effect of corticosteroids in 10 cases of methimazole-induced agranulocytosis. Endocrinol Jpn 28: 823-827, 1981. 
8. Johnsen H, Husebekk A, Skjelbakken T. Severe antibody-mediated agranulocytosis. Int J Lab Hematol 30: 71-74, 2008.

9. Fumeaux Z, Beris P, Borisch B, et al. Complete remission of pure white cell aplasia associated with thymoma, autoimmune thyroiditis and type 1 diabetes. Eur J Haematol 70: 186-189, 2003.

10. Maher GM, Hartman KR. Detection of antineutrophil autoantibodies by flow cytometry: use of unfixed neutrophils as antigenic targets. J Clin Lab Anal 7: 334-340, 1993.

11. Matsuyama N, Kojima Y, Hirayama F, et al. Simultaneous five cell-lineage flow cytometric analysis system for detection of leucocyte antibodies. Transfus Med 16: 111-118, 2006.

12. Yasui $\mathrm{K}$, Miyazaki T, Matsuyama N, et al. Establishment of cell lines stably expressing HNA-1a, $-1 \mathrm{~b}$, and $-2 \mathrm{a}$ antigen with low background reactivity in flow cytometric analysis. Transfusion (Paris) 47: 478-485, 2007.

13. Yasui K, Angata T, Matsuyama N, et al. Detection of anti-Siglec14 alloantibodies in blood components implicated in nonhaemolytic transfusion reactions. Br J Haematol 153: 794-796, 2011.

14. Amakishi E, Hayashi T, Koh Y, et al. A new transfectant panel cell line-based MoAb-independent antigen capture assay system for detection of CD36 antibody. Vox Sang 106: 368-371, 2014.

15. Yagasaki H, Shichino H, Ohara A, et al. Immunosuppressive therapy with horse anti-thymocyte globulin and cyclosporine as treatment for fulminant aplastic anemia in children. Ann Hematol 93: 747-752, 2014.

16. Andres E, Maloisel F, Zimmer J. The role of haematopoietic growth factors granulocyte colony-stimulating factor and granulocyte-macrophage colony-stimulating factor in the management of drug-induced agranulocytosis. Br J Haematol 150: 3-8, 2010.
17. Andersohn F, Konzen C, Garbe E. Systematic review: agranulocytosis induced by nonchemotherapy drugs. Ann Intern Med 146: 657-665, 2007.

18. Akhtari M, Curtis B, Waller EK. Autoimmune neutropenia in adults. Autoimmun Rev 9: 62-66, 2009.

19. Capsoni F, Sarzi-Puttini P, Zanella A. Primary and secondary autoimmune neutropenia. Arthritis Res Ther 7: 208-214, 2005.

20. Youinou P, Jamin C, Le Pottier L, Renaudineau Y, Hillion S, Pers JO. Diagnostic criteria for autoimmune neutropenia. Autoimmun Rev 13: 574-576, 2014.

21. Lucas G, Porcelijn L, Fung YL, et al. External quality assessment of human neutrophil antigen (HNA)-specific antibody detection and HNA genotyping from 2000 to 2012. Vox Sang 105: 259-269, 2013.

22. Bux J, Chapman J. Report on the second international granulocyte serology workshop. Transfusion (Paris) 37: 977-983, 1997.

23. Smith MA, Smith JG. The use of granulocyte colony-stimulating factor for treatment of autoimmune neutropenia. Curr Opin Hematol 8: 165-169, 2001.

24. Patterson TF, Thompson GR 3rd, Denning DW, et al. Practice Guidelines for the Diagnosis and Management of Aspergillosis: 2016 Update by the Infectious Diseases Society of America. Clin Infect Dis 63: e1-e60, 2016.

The Internal Medicine is an Open Access article distributed under the Creative Commons Attribution-NonCommercial-NoDerivatives 4.0 International License. To view the details of this license, please visit (https://creativecommons.org/licenses/ by-nc-nd/4.0/).

(C) 2017 The Japanese Society of Internal Medicine Intern Med 56: 2199-2203, 2017 